\title{
Plasma deposition of amorphous silicon films: an overview on some open questions
}

\author{
P. Capezzuto and G. Bruno \\ Centro di Studio per la Chimica dei Plasmi, C.N.R. \\ Dipartimento di Chimica, Università di Bari \\ Via Amendola, 173 - 70126 Bari, Italy.
}

\begin{abstract}
Results on amorphous silicon deposition by $\mathrm{SiH}_{4}, \mathrm{SiF}_{4}$ and $\mathrm{SiCl}_{4}$ glow discharges are discussed so as to better understand the plasma phase processes leading to the growth precursors, the plasma/surface interaction and the microscopic parameters affecting the material properties. In particular, the chemical activity of both silicon radicals, hydrogen and halogen atoms, as well as charged particles in the gas phase and on the surface is examined.
\end{abstract}

\section{INTRODUCTION}

The remarkable disequilibrium existing among the various degrees of freedom of the particles present in low pressure glow discharges accounts for the unique feature of the plasma to generate chemically reactive species at low temperature. This explains the recent development of plasma technique in the production and treatment of "new" materials of technological interest. The increasing utilization of glow discharge in the deposition of amorphous silicon films originates from the discovery at Dundee University that hydrogenated amorphous silicon $(\mathrm{a}-\mathrm{Si}: \mathrm{H})$ deposited in silane glow discharge can undergo $\mathrm{n}$ and $p$ doping. The consequent interest in this material was at first concentrated on its utilization in low-cost photovoltaic devices and later on electrophotography, image pickup systems and on field effect transistors (FET). Besides silane ( $\mathrm{SiH}_{\text {) }}$ silicon halides ( $\left.\mathrm{SiF}, \mathrm{SiCl}_{4}\right)$, are utilized as feeding reactants, since halogen atoms, like hydrogen, have been ${ }^{4}$ found to act in the films as dangling bond terminators, thus decreasing the state density in the energy gap.

The technology of thin films produced by plasma deposition has been fast outrunning the scientific understanding of the chemical processes involved as well as their influence on the material properties. The great deal of work carried out in this direction over the last years is due to the need for improving the photovoltaic and electronic quality of the material. Another goal which is still the subject of ongoing reasearch is the increase of the deposition rate for the large scale production to be economically convenient.

One of the problems regarding deposition systems is the inadequate characterization of the discharges being used by different groups. However, some techniques have been optimized for the diagnostics of these systems and are going to become common tools for plasma characterization. Among them, Optical Emission Spectroscopy (OES) and liass Spectrometry (MS) are widely utilized. More sophisticated and expensive techniques, like Laser Induced Fluorescence (LIF) and Coherent Anti-Stokes Raman Spectroscopy (CARS), are less utilized although they are more adapt in giving quantitative results.

The present work concerns some of the unsolved problems which need definite answers. 


\section{OPEN QUESTIONS}

A complete understanding of all the processes involved in plasma deposition of silicon films is still rather difficult to obtain, due to the contemporary presence of different phases (gas and solid) and of different types of active species (molecules, radicals, atoms, ions and electrons). Some aspects of this complex matter have been investigated successfully by many authors. Neverthless, a number of problems have not yet been solved and, despite the growing efforts to overcome them recently, some crucial questions still remain.

It is difficult to interpret different experimental evidence within the same framework since the results are obtained from completely different apparatus or, in some cases, from apparatus with only a few points in common. In addition, the absence of meaningful diagnostic techniques on the same system does not contribute any further insight. To our opinion these are the main causes of the unsolved questions regarding the identity of plasma and plasma/surface processes leading to deposition.

In the following we will analyze some of these open questions and in particular we will go into details about:

i. plasma phase processes leading to growth precursors;

ii. plasma/surface interaction;

iii. microscopic parameters affecting the material properties.

\section{Plasma phase processes as sources of growth precursors}

The common recurring problem in most of the plasma chemical systems depositing silicon films from $\mathrm{SiH}_{4}, \mathrm{SiF}$ and $\mathrm{SiCl}_{4}$ is identification of the gas processes responsible for the production of the major active species. This first step, together with the measurement of the deposition rate and the of material properties can lead to the identification of the growth precursors. A lot of work has been carried out in this direction on the three system mentioned, especially on silane glow discharges. However, the results obtained are, to some extent, controversial and far from definitive.

The current hypotheses found in literature on the identity of the growth precursors collected for different feeding mixtures are shown in Table 1.

Table 1.-Growth precursors hypothesized in the deposition of silicon films from different feeding mixtures.

\begin{tabular}{|c|c|c|c|}
\hline Gas feed & Precursors & Experimental Approach & Refs. \\
\hline $\mathrm{SiH}_{4}-\mathrm{H}_{2}$ & $\mathrm{SiH}$ & $\begin{array}{l}\text { Magnetically confined } \\
\text { plasma; OES }\end{array}$ & (9) \\
\hline pure $\mathrm{SiH}_{4}$ & $\mathrm{SiH}$ & r.f. plasma; OES, MS & (47) \\
\hline pure $\mathrm{SiH}_{4}^{4}$ & $\mathrm{SiH}_{2}$ & r.f. plasma; OES & (3) \\
\hline pure $\mathrm{SiH}_{4}^{4}$ & $\mathrm{SiH}_{2}^{2}$ & $\begin{array}{l}\text { d.c. plasma; MS chemical } \\
\text { relaxation technique }\end{array}$ & (2) \\
\hline $\mathrm{SiH}_{4}-\mathrm{H}_{2}(\mathrm{He})$ & $\mathrm{SiH}_{2}$ & r.f. plasma; MS & $(48)$ \\
\hline $\mathrm{SiH}^{4} / \mathrm{SiH}_{4}^{2} \mathrm{Ar}$ & $\mathrm{SiH}_{3}^{2}$ & d.c. plasma; MS & (5) \\
\hline pure $\mathrm{SiH}_{4}^{4}$ & $\mathrm{SiH}_{3}^{3}$ & d.c. static plasma; MS & (6) \\
\hline $\mathrm{SiH}_{4}-\mathrm{Ar}^{4}$ & $\mathrm{SiH}_{3}^{3}$ & $\begin{array}{l}\text { r.f. plasma; } \\
\mathrm{H} \text { content by NMR }\end{array}$ & (4) \\
\hline $\mathrm{SiH}_{4}$ & $\mathrm{SiH}_{3}$ & $\begin{array}{l}\text { Hg-photosensitized } \\
\text { decomposition }\end{array}$ & (8) \\
\hline pure $\mathrm{Si}_{2} \mathrm{H}_{6}$ & $\mathrm{Si}_{2} \mathrm{H}_{\mathrm{y}}$ & r.f. plasma; OES, MS & (47) \\
\hline Pure $\mathrm{SiF}_{4}$ & SiF & r.f. plasma; OES & (22) \\
\hline $\mathrm{SiF}_{4}-\mathrm{H}_{2}{ }^{4}$ & $\operatorname{SiF}_{\mathbf{x}}$ & $\begin{array}{l}\text { r.f. plasma; OES, LIF, } \\
\text { electrical probes }\end{array}$ & $(11)(13)(49)$ \\
\hline $\mathrm{SiCl}_{4}-\mathrm{H}_{2}$ & $\mathrm{SiCl}_{2}$ & r.f. plasma; MS & $(50)$ \\
\hline $\mathrm{SiCl}_{4}^{4}-\mathrm{H}_{2}^{2}-\mathrm{Ar}$ & $\mathrm{SiCl}_{2}^{2}, \mathrm{SiCl}_{4}$ & r.f. plasma; MS, OES & $(14)(16)$ \\
\hline
\end{tabular}


Though far from being exhaustive, the number of references reported denotes the enormous interest towards this problem. However, the observed discrepancy regarding the precursor identity can often be due to the different experimental approaches used.

A rationalization of processes leading to gas phase precursors can be obtained if the main plasma reactions are summarized as in the following:

i. electron-molecule reactions

$$
\begin{aligned}
& \operatorname{Six}_{4}+\mathrm{e} \longrightarrow \operatorname{Six}_{n}+(4-n) x+e \\
& \operatorname{Six}_{4}+\mathrm{e} \longrightarrow \operatorname{Six}_{n}^{+}+(4-n) x+e+e
\end{aligned}
$$

ii. neutral-neutral reactions

$$
\begin{aligned}
& \mathrm{H}+\mathrm{SiX}_{4} \longrightarrow \mathrm{Six}_{3}+\mathrm{HX} \\
& \mathrm{Six}_{4}+\mathrm{SiX}_{\mathrm{n}} \longrightarrow \mathrm{Si}_{2} \mathrm{X}_{4+\mathrm{n}} \rightarrow \rightarrow . \mathrm{Si}_{\mathrm{n}} \mathrm{X}_{\mathrm{m}}
\end{aligned}
$$

iii. ion-molecule reactions

$$
\mathrm{SiX}_{\mathrm{n}}^{+}+\mathrm{SiX}_{4} \longrightarrow \mathrm{Si}_{2} \mathrm{X}_{\mathrm{m}}^{+}+(4+\mathrm{n}-\mathrm{m}) \mathrm{X}
$$

which can refer to $\mathrm{SiH}_{4}, \mathrm{SiF}_{4}$ and $\mathrm{SiCl}_{4}$ systems $(\mathrm{X}=\mathrm{H}, \mathrm{F}, \mathrm{Cl})$

From the data in Table 1 and the therein quoted references, it turns out that the predominant species present in silane plasma, and therefore the most probable growth precursors in the gas phase, can be either $\mathrm{SiH}$ or $\mathrm{SiH}_{2}$ or $\mathrm{SiH}_{3}$ radicals. These species can have different origin, according to which of the three principal reactions reported in the previous scheme is invoked (c.f. G. Turban, ref.1). This in turn depends on the particular conditions (pressure, power...) in which the plasma operates. In particular, the electron induced fragmentation of silane (react.1) is the main source of $\mathrm{SiH}_{2}$ for Veprek (ref.2), of $\mathrm{SiH}_{2}$ and $\mathrm{SiH}_{3}$ for Kampas (ref.3,4) and of $\mathrm{SiH}_{3}$ for Gallagher (ref.5). In addition, Veprek ${ }^{2}$ reportes that the abstraction reaction (3) giving $\mathrm{SiH}_{3}$ may in some cases contribute

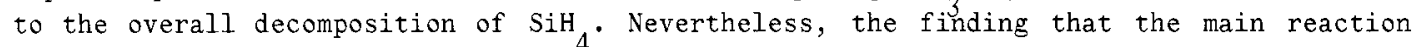
channel is for Veprek the $\mathrm{SiH}_{4}$ electron impact dissociation to give $\mathrm{SiH}_{2}$ is well substantiated by the results obtained with chemical relaxation mass spectrometry (ref.2).

The predominant presence attributed by Gallagher to $\mathrm{SiH}_{3}$ radical, is due to both reactions (1) and (3) and is supported by threshold-ionization mass spectrometry measurements. A different origin has been assigned to $\mathrm{SiH}_{3}$ radicals by Longeway (ref.6) who invokes for most of its generation ion-molecule reactions which are generally several orders of magnitude faster than radical-molecule reactions. The prevailing presence of $\mathrm{SiH}_{3}$ on $\mathrm{SiH}_{2}$ has been in this case stated after the addition of No, a selective $\mathrm{SiH}_{3}$ radical scavenger, and is attributed to the predominance of kinetic factors on the energetically favoured generation of $\mathrm{SiH}_{2}$. Criticism of NO used as an $\mathrm{SiH}_{3}$ scavenger has been expressed by Veprek $($ ref.7).

In order to study the interaction of $\mathrm{SiH}_{3}$ radicals with the surface of the growing silicon films Perrin et al. (ref.8), has utilized Hg-photosensitized decomposition of pure $\mathrm{SiH}_{4}$ and pure $\mathrm{Si}_{2} \mathrm{H}_{6}$. The author found that when operating in the absence of ions and electrons, this system ${ }^{2}$ ields almost exclusively $\mathrm{SiH}_{3}$ radicals.

Hamasaki et al. (ref.9) assign the origin of SiH radicals which, together with $\mathrm{H}$ atoms has been found to be the growth precursors to highly effective abstraction reactions by atomic hydrogen (react.3).

Recently, a detailed description of reactions occurring in silane glow discharge and relative rate constants has been given by M.J. Kushner (ref.10). On the basis of a plasma chemistry computed model including about 30 reactions, the author claims that $\mathrm{SiH}_{2}$ and $\mathrm{SiH}_{3}$ are the main radicals in $\mathrm{SiH}_{4}-\mathrm{H}_{2}$ and $\mathrm{SiH}_{4}-\mathrm{Ar}$ discharges and that the higher silane radicals $\mathrm{Si}_{\mathrm{n}} \mathrm{H}_{\mathrm{m}}$ predominate in pure ${ }^{4} \mathrm{SiH}_{4}$ and $\mathrm{SiH}_{4}^{4}-\mathrm{Si}_{2} \mathrm{H} 6$ discharges. These results have been 
utilized by the author in an integrated computed model on the deposition mechanism in order to account for some experimental data.

The deposition of hydrogenated and halogenated amorphous silicon (a-Si:H,X) starting from its halides, mainly $\mathrm{SiF}$ and $\mathrm{SiCl}$, has had a remarkable development since it has been proved that the grown material exhlbits optical and electrical properties comparable with those found for a-Si:H. An important problem which arises with halogenated fed plasmas $\left(\mathrm{SiCl}_{4}, \mathrm{SiF}_{4}\right)$ is the "chemical activity" shown by the plasma species with respect to the surface, under different experimental conditions. It is well known that plasma fed with silicon halides can be active both for etching and deposition processes, depending on the relative aboundance of halogen atoms $(\mathrm{Cl}, \mathrm{F})$ and silicon radicals ( $\mathrm{SiCl}, \mathrm{SiF}$ ), which are etchant species and building blocks for film formation, respectively. 'In spite of this, most of the monosilicon radicals present in the plasma phase are emissive species and therefore they are detectable by optical emission spectroscopy, which is a widely used diagnostic tool in plasma systems. In particular, OES technique allows $\mathrm{SiCl}_{2}, \mathrm{SiF}_{2}$ and $\mathrm{SiF}_{3}$ excited species to be detected, whereas the equivalent species $\mathrm{SiH}_{2}$ and $\mathrm{SiH}_{3}$ are not detêctable in silane discharges. For this reason the investigation of the halogenated system can gain a deeper insight in the processes involved in the homogeneous plasma phase and, consequently, a better understanding of the heterogeneous processes occurring on the deposition surface. Again, the processes of the above mentioned reaction schemes (eqs. 1-5) have been involved as formation channels for SiX radicals in halogenated systems. In addition, the presence of hydrogen in the feed is fundamental for silicon film deposition, since its scavenger role on halogen atoms prevents the etching process from being effective. The process:

$$
\mathrm{H}_{2}(\text { or } \mathrm{H})+\mathrm{X} \longrightarrow \mathrm{HX}+\mathrm{H}
$$

has therefore to be included in the reaction scheme, when it applies to halogenated systems.

To date, there are less data available in literature concerning the deposition mechanism of $\mathrm{SiX}$ systems than for $\mathrm{SiH}_{4}$. Neverthless, there are some significant contributions on plasma phase characterization, as reported in refs. 11-16.

We have studied the deposition of silicon films occurring in a plasma reactor fed with $\mathrm{SiCl}_{4}-\mathrm{H}_{2}$ mixtures, focussing our attention on the analysis of gas phase species and on the study of the deposition mechanism (ref.14). To do this we have utilized three on line diagnostic techiniques: (i) Optical Emission Spectroscopy (OES) for the analysis of the emitting species present in the plasma phase; (ii) Mass Spectrometry (MS) for the analysis of the stable species coming out from the reactor, in order to obtain the extent of $\mathrm{SiCl}$ depletion; (iii) Laser Interferometry (LI) for the "in situ" measurements of the deposition rate. More recently, we have carried out the same investigation on a plasma reactor fed with $\mathrm{SiF}_{4}-\mathrm{H}_{2}$ mixtures by utilizing the same diagnostic techniques as before.

In the deposition from $\mathrm{SiCl}_{4}-\mathrm{H}_{2}$ mixture many experimental parameters have been varied (feed composition, total flow rate, substrate temperature and total pressure), in order to affect the plasma phase composition and to observe the correspondent effect on the rate of the surface process. With this respect it has been found that the plasma phase composition is sensitive to the $\mathrm{H}_{2}$ /Ar ratio, when molecular hydrogen in the feed is progressively substituted by argon. The effect of the argon molar fraction in $\mathrm{H}_{2}+\mathrm{Ar}$ mixture on the relative emission intensity of the gaseous species, and on the deposition rate as obtained by OES and LI, respectively, is shown in Fig.1. The emission intensity of each species has been normalized to that of Ar according to the actinometric method (ref.17).

The origin of the $\mathrm{SiCl}_{\mathrm{x}}$ radicals reported in the figure can be attributed to electron-molecule and neutral-neutral reactions:

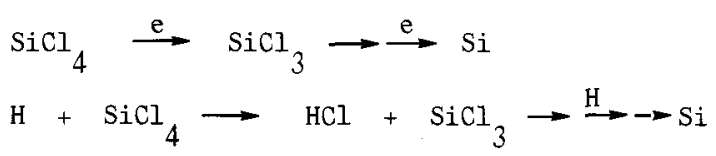

according to eqs.1 and 3 . 
Ion-molecule reactions of the type reported in eq.5:

$$
\mathrm{SiCl}_{3}^{+} \stackrel{\mathrm{SiCl}_{4}}{\longrightarrow} \mathrm{Si}_{2} \mathrm{Cl}_{5}^{+} \stackrel{\mathrm{SiCl}_{4}}{\longrightarrow} \rightarrow \mathrm{Si}_{\mathrm{x}} \mathrm{Cl}_{\mathrm{y}}^{+}+\mathrm{Cl}_{2}
$$

which can contribute to the total $\mathrm{SiCl}_{4}$ depletion, have not been invoked for the deposition mechanism proposed under experimental conditions of Fig. 1 (ref14), since no poly-silicon fragments have been observed by mass spectrometry. However, under more drastic conditions (higher power and pressure), ion-molecule insertion reactions (9) have been found to be effective (ref.18).

A careful analysis of Fig. 1 shows that the direct electron impact process (7) is probably the main dissociation channel of $\mathrm{SiCl}$ and therefore it turns out that electron density plays a fundamental role. In fact, the strong decrease of SiCl density observed when a small percentage of $\mathrm{H}_{2}$ is added to the $\mathrm{SiCl}_{-}-\mathrm{Ar}$ mixture can be attributed to a decrease of electron concentration with energy sufficient for process (7) (ref.18,19). The scavenging effect of hydrogen on $\mathrm{Cl}$ atoms reported in reaction (6) is well illustrated by their relative density trends in the figure

The concentration of hydrogen in halogenated feeds is crucial also in $\mathrm{SiF}-\mathrm{H}_{2}$ systems (refs.19,20). In fact, as reported in ref.19 only in a well defined range of 5 iF $\frac{2}{4} / \mathrm{H}_{2} \mathrm{ratio}$ (0.5-13) a deposition is observed with a rate up to $3 \AA / \mathrm{sec}$, while outside that range the deposition rate is below the detection limit. When a predeposited sample is submitted to a pure SiF discharge an etching process is observed. Another effect observed with hydrogen addition ${ }^{4}$ is a large variation of the electron concentration which can account for the change of distribution of SiF radicals in the plasma phase, i.e. the dissociation of SiF is mainly due to direct electron impact. Processes involving electrons have also been invoked by N. Mutsukura et al. (ref.11) and H.U. Lee et al. (refs.13,21). The latter has found that also $\mathrm{H}$ atoms can contribute to $\mathrm{SiF}_{4}$ dissociation via reaction (3).

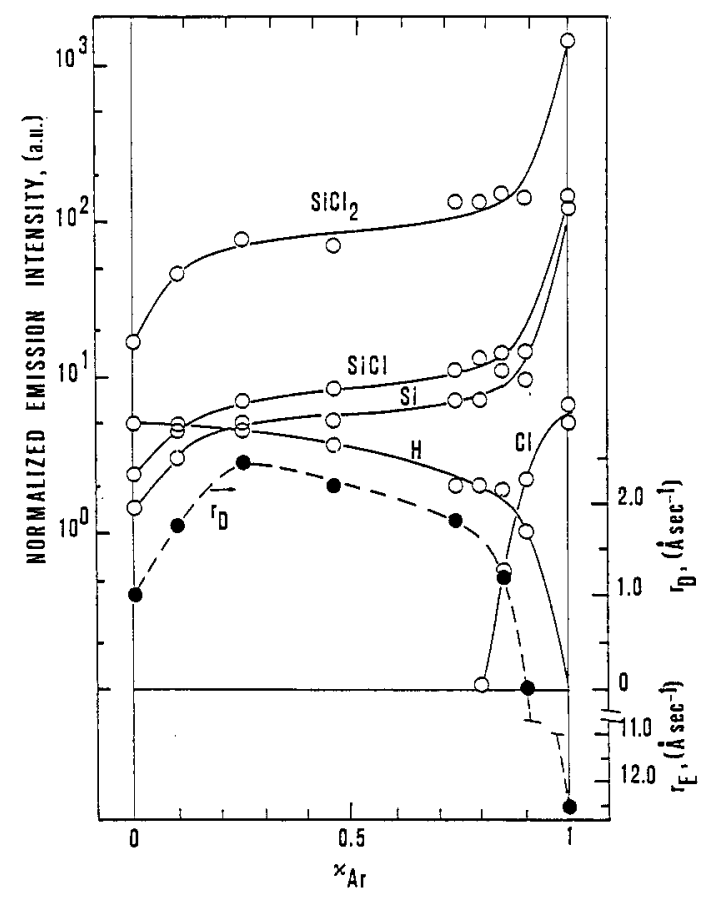

Fig.1 -Intensity of emitting species(io) normalized to Ar peak at $770 \mathrm{~nm}$ vs $\mathrm{H}_{2}-\mathrm{Ar}$ mixture composition, $\boldsymbol{x}_{A r}$. Values of the deposition $r_{D}$ and etch rate, $r_{E}(\bullet)$ refer to the right hand scale. $\left(\mathrm{SiCl}_{4}:\left(\mathrm{H}_{2}+\mathrm{Ar}\right) / 5: 95 ; 60 \mathrm{sccm} ; 1\right.$ torr, 10 watts; $\mathrm{T}_{\mathrm{D}}=300^{\circ} \mathrm{C}$ ). 


\section{Plasma-surface interaction}

In this section we describe some aspects of the interaction between plasma phase active species and the deposition surface, due to the relevant role this interactions has in defining the chemical and physical properties of the deposited material.

Once chemical active species (neutral and charged) are produced in the gas phase, problems arise about what kind of interaction they have with the deposition surface and how they contribute to the deposition itself. Among others, three processes are worthy of mention:

i. adsorption-desorption processes.

They are generally considered intermediate steps, which the overall deposition process is forced to go through.

ii. surface reactive processes.

They include mainly chemical reactions among adsorbed species or between adsorbed and gaseous radicals and lead to the formation of free bond silicon species for the material growth. These processes also include the reactions involving silicon species bonded to the lattice and resulting in material etching.

iii. surface bombardment by charged particles.

This process strongly depends on the electrical parameters of the plasma and, by affecting the above mentioned surface processes, can influence both the kinetics of the overall process and the material properties.

There can be no doubt that all the above mentioned processes are involved in the deposition mechanism of silicon films. Nevertheless, direct evidence of reactive and unreactive processes occurring on the surface are not well supported by the literature data. The predominant role of one of these processes, usually the rate limiting step, is evidenced when a kinetic approach is utilized to investigate the deposition model. In some cases it has been reported that the processes involving neutral species are important in determining the kinetics of growth (ref.1,22). In others it has been underlined that ions and electrons bombarding the growth surface can control the rate of the overall process (ref.7). Indeed, in both cases it has been claimed that the chemisorption of active species is a preliminary necessary step.

Some results supporting the presence of a chemisorption process in $\mathrm{SiCl}_{4}-\mathrm{H}_{2}$ glow discharge are reported in Figs 2 and 3.

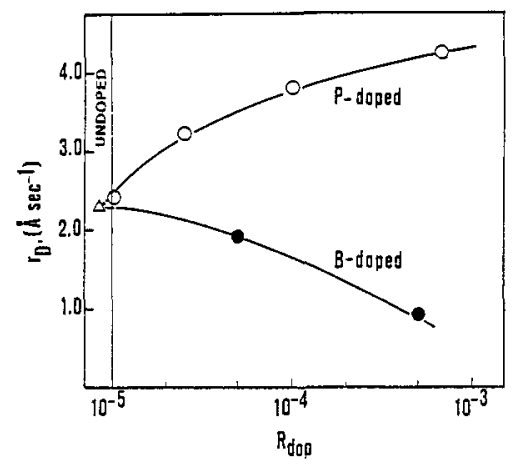

Fig.2 -Deposition rate, $r_{D}$ of doped $(0,0)$ and undoped $(\Delta)$ samples $\mathrm{VS} \mathrm{PH}_{3}$ and $\mathrm{B}_{2} \mathrm{H}_{6}$ addition, $\mathrm{R}_{\mathrm{dop}}\left(=\Phi_{\mathrm{dop}} \Phi_{\mathrm{T}}\right)$ ? $\left(\mathrm{SiCl}: \mathrm{H}_{2}: \mathrm{Ar} / 5: 71: 24 ; 68 \mathrm{Sccm}\right.$; 1 torr; 10 watts; $T_{D}=300^{\circ} \mathrm{C}$ ).

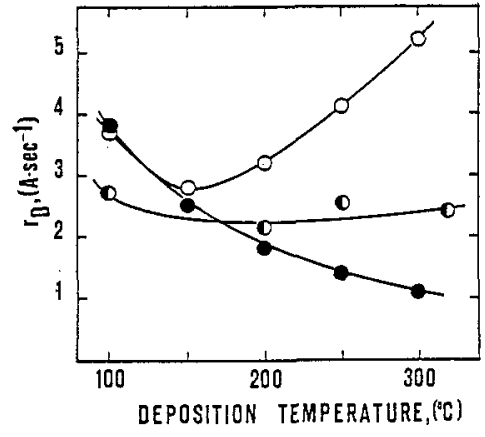

Fig.3 -Effect of the deposition temperature on the deposition rate $r_{D}$ during the growth of undoped $(\mathbf{O})$ and doped $(\mathbf{O}, \mathbf{0})$ $\mathrm{Si}: \mathrm{H}, \mathrm{Cl}$ films. ( $\mathrm{R}=10^{-3}$, for other parameters see capt? of Fig. 2).

The observed increase of the deposition rate with the addition of phosphine ( $\mathrm{PH}_{3}$ ) and the correspondent decrease with diborane $\left(\mathrm{B}_{2} \mathrm{H}_{6}\right)$ can be explained within the surface chemisorption theory (ref.22). The same effect of dopant addition on $r$ has been found by $R$. Manory et al. (ref.23), who attributed it to differences in the surface morphology. $\mathrm{SiCl}$ active species produced in the plasma phase are chemisorbed on the substrate surface according to:

$$
\mathrm{SiCl}_{\mathbf{x}} \text { (gas) } \stackrel{\mathrm{K}_{1}}{\longrightarrow} \mathrm{SiCl}_{\mathbf{x}}(\text { ads })
$$

where $K_{1}$ is the equilibrium constant, which depends on the temperature and on the kind of surface (i.e. undoped, $\underline{n}$ and $\underline{p}$ doped). The different behaviour of the growth rate with the 
deposition temperature according to the different nature of the surface is clearly visible in Fig. 3. Similar results have been found in the deposition of doped and undoped a-Si:H,F films from $\mathrm{SiF}_{4}-\mathrm{H}_{2}$ mixtures (ref.19)

The presence of chemisorption processes has also been stressed by many authors both in halogenated systems (refs.22,23) and in silane plasma (refs.10,24,25,26). However, in the latter case the effect of the dopant addition on the deposition rate has given opposite trends with respect to those reported in Fig. 2 (refs.27,28). Some uncertainties on the predominant chemisorbed species are still present, in analogy with the mentioned open questions about the main radicals present in the gas phase. In relation to this, we have suggested $\mathrm{SiCl}_{2}$ as the prevalent radical chemisorbed on the surface for a-Si:H,Cl deposition (ref.14). However, exotic hypotheses about the possibility that $\mathrm{SiH}_{4} \mathrm{SiCl}_{4}$ and $\mathrm{SiF}_{4}$ are dissociatively chemisorbed have also been formulated.

Veprek et al. (ref.26) suggests that ion-impact-induced fragmentation of silane on the surface is the dominant reaction channel:

$$
\mathrm{SiH}_{4} \stackrel{\text { ions }}{\longrightarrow} \mathrm{SiH}_{\mathrm{x}}(\mathrm{ads})
$$

on the basis of a linear relationship found between the deposition rate and the flux of the low energy ions $(<10 \mathrm{eV}$ ) towards the surface. Also Robertson et al. (ref.5) invokes a direct dissociative chemisorption of silane on open surface sites:

$$
\mathrm{Si}^{\cdot}+\mathrm{SiH}_{4} \longrightarrow \mathrm{SiHSiH}_{3}
$$

where the dangling bonds on silicon are obtained by $\mathrm{H}$ atom abstraction

$$
\mathrm{SiH}+\mathrm{H} \longrightarrow \mathrm{Si}^{\circ}+\mathrm{H}_{2}
$$

In this case the overall growth kinetics is therefore controlled by the flux of $H$ atoms impinging on the surface.

A dissociative chemisorption of $\mathrm{SiCl}$ has also been invoked to explain the results obtained in $\mathrm{SiCl}_{4}-\mathrm{H}_{2}$ glow discharge (ref.29,16), by varying the substrate temperature (see Fig. 4).

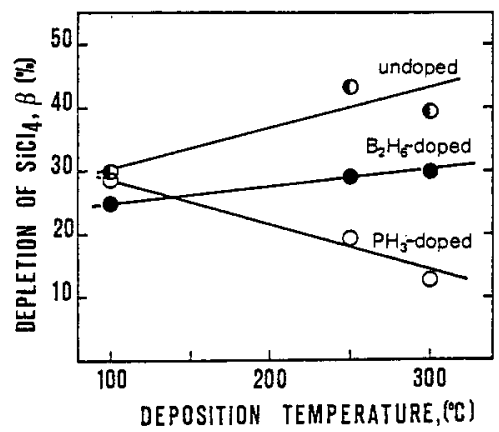

Fig.4 -Effect of the deposition temperature on the depletion of $\mathrm{SiCl}_{4}, \beta$ during the growth of undoped (O) and doped $(0,0) \mathrm{Si}: \mathrm{H}, \mathrm{Cl}$ films . $\left(R_{d o p}=10^{-3}\right.$, for other parameters see capt. of Fig. 2).

The different influence that the type of material (undoped, $\underline{n}$ and $\underline{p}$ doped) has on $\mathrm{SiCl}_{4}$ depletion, $\beta$, indicates a direct dissociation of $\mathrm{SiCl}$ on the surface. on the basis of this result the eq.10 can be better iflustrated as follows:

$$
\mathrm{SiCl}_{4}(\text { gas }) \rightleftharpoons \mathrm{SiCl}_{\mathbf{x}}(\text { ads }) \rightleftharpoons \mathrm{SiCl}_{\mathbf{x}} \text { (gas) }
$$

Also in this case, as in ref.5, it has been found that $H$ atoms play an important role in a reactive process on the surface with adsorbed active species $\mathrm{SiCl}_{\mathbf{x}}$ :

$$
\mathrm{SiCl}_{\mathrm{x}}(\mathrm{ads})+\mathrm{H}(\operatorname{gas}) \longrightarrow \mathrm{SiCl}_{(\mathrm{x}-1)}(\mathrm{ads})+\mathrm{HCl}(\operatorname{gas})
$$

where the produced free-bond silicon species are intermediate in the formation of silicon to silicon bonds:

$$
-\operatorname{SiCl}_{(\mathrm{x}-1)}(\mathrm{ads})+-\mathrm{SiCl}_{(\mathrm{x}-1)}(\mathrm{ads}) \longrightarrow \int_{\operatorname{SiCl}}^{\mathrm{SiCl}}(\mathrm{x}-1) \text { (solid) }
$$


The essential role of $\mathrm{H}$ atoms and surface free-bond silicon species on the deposition of $\mathrm{Si}: \mathrm{H}, \mathrm{F}$ films from $\mathrm{SiF}-\mathrm{H}_{2}$ plasmas has been also emphasized by Matsuda et al. (ref.22). These workers propose on the basis of thermodynamic considerations a deposition model which involves surface reaction steps similar to the reactions (15) and (16).

A kinetic formulation of the surface processes involved in eqs. $(14,15,16)$ leads to the expression for the deposition rate:

$$
\mathrm{r}_{\mathrm{D}} \propto[\mathrm{H}]\left[\mathrm{SiCl}_{\mathrm{x}}\right]
$$

which shows reaction (15) as rate-limiting step. This has been verified in our previous work (ref.14), where no assumption on the value of $x$ could be done. Recently, further results on this aspect have been obtained by studying the effect of total flow rate variation both on the deposition rate and on the active species concentration as well as on the SiCl concentration near the substrate (ref.16). These results are shown in Fig. 5, where the relative concentrations of $\mathrm{H}, \mathrm{Si}, \mathrm{SiCl}$ and $\mathrm{SiCl}_{2}$ have been obtained by OES measurements, according to the actinometric method, while SiCl $_{4}$ density has been sampled by mass spectrometry.

The linear relationship in eq.17 was verified, by utilizing the data in Fig. 5 , with both $\mathrm{SiCl}_{2}$ and $\mathrm{SiCl}_{4}$ densities, as reported in $\mathrm{Fig} .6$.

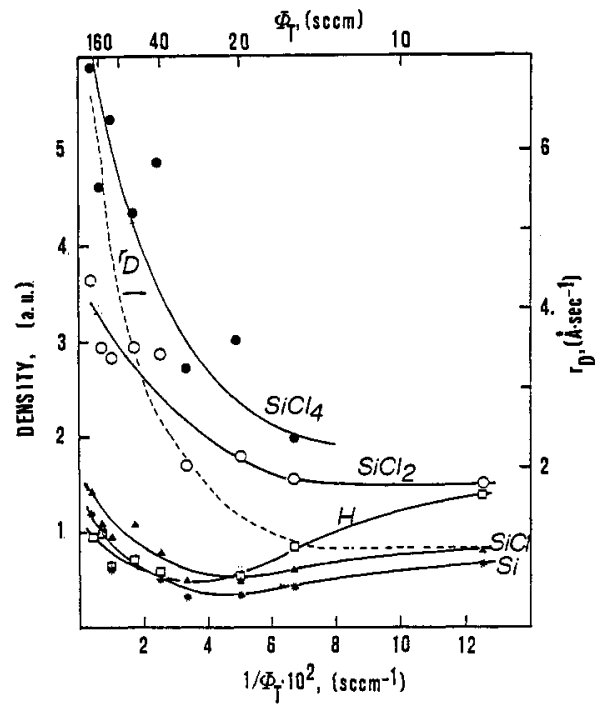

Fig.5 - Trends of $\mathrm{SiCl}_{\mathrm{x}}$ and $\mathrm{H}$ density and deposition rate $r_{0}$ in plasma fed with $\mathrm{SiCl}-\mathrm{H}_{2}$ Ar (5:71:24) mixtures at different total flow rate $\Phi_{T}$. (see capt. of Fig.2 for other parameters).

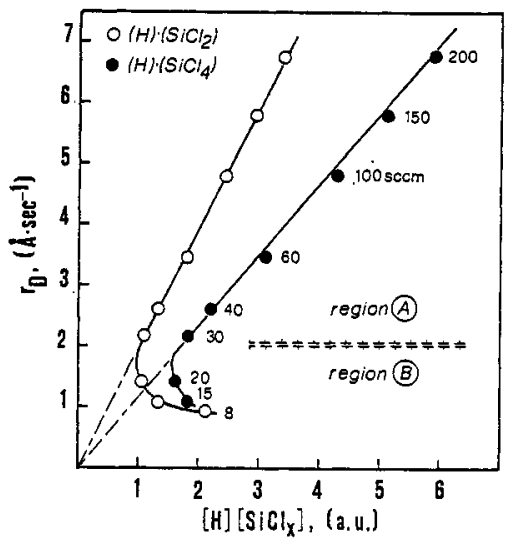

Fig.6 -Deposition rate, $r_{D}$ vs the product of the density of hydrogen atoms and $\mathrm{SiCl}_{2}$ (O) or SiCl () . Region (A) and (B) denote the zone of kinetic and mass transfer limitation, respectively.

The fact that the experimental points at low flow rate $\left(\Phi_{\mathrm{T}}<30 \mathrm{sccm}\right)$ do not fit the linear relationship is a clear evidence that in this region the rate-limiting step in the deposition of silicon is the supply of chemical active particles to the surface. In this case the overall rate of plasma deposition is determined entirely by the diffusion rate of the chemically active species to the growth surface and it does not have anything in common with the true kinetics of the surface processes. In the region at high flow rate ( $\Phi_{T} \geq 30$ $\mathrm{sccm}$ ) the deposition of the material is determined by the true rate of the reaction on the surface, i.e. the deposition process takes place in the kinetic region.

On the basis of the above results, we believe that the deposition of silicon films by $\mathrm{SiCl}$ glow discharges, under conditions in which chlorine atoms are absent in the gas phase (see Fig.1), can be depicted by the following scheme:

$$
\begin{aligned}
& \mathrm{SiCl}_{4} \text { (gas) } \rightleftarrows \mathrm{SiCl}_{2} \text { (ads) } \rightleftarrows \mathrm{SiCl}_{2} \text { (gas) } \\
& +\mathrm{H} \\
& -\mathrm{SiCl}(\mathrm{ads}) \longrightarrow \mathrm{film}
\end{aligned}
$$


in which both $\mathrm{SiCl}_{4}$ and $\mathrm{SiCl}_{2}$ species are the growth precursors. They can infact give $\mathrm{SiCl}_{2}$ chemisorbed species, active intermediates to produce free-bond silicon species $(-\mathrm{SiCl})$, which in turn link to each other to give the silicon film. This model predicts that the deposition rate should be proportional to the $\mathrm{SiCl}_{2}$ surface coverage and hence, through chemisorption equilibria, to $\mathrm{SiCl}_{4}$ and $\mathrm{SiCl}_{2}$ concentration in the gas phase, as verified in Fig. 6. The model also predicts ${ }^{4}$ the presence of an equilibrium between $\mathrm{SiCl}_{4}$ and $\mathrm{SiCl}_{2}$ densities in the gas phase for given surface temperature and this appears 4 to be well substantiated by the linear correlation of Fig. 7 .

When chlorine atoms are present in the gas phase, the described model is no longer sufficient, due to the competition between deposition and etching. This effect is well illustrated in Fig.1, in the region where the argon molar fraction is by far prevalent on that of hydrogen in the feed. The decrease of the deposition rate even in the presence of an increase of silicon containing species, is similar to the decrease of $H$ atoms and implies the forementioned important role of partnership played by hydrogen in the deposition. In addition, the scavenging effect of hydrogen on $\mathrm{Cl}$ (react. 6) is also extinguishing and the presence of $\mathrm{Cl}$ atoms starts to increase. The etchant role of the plasma in the non-deposition region has been verified by submitting fresh predeposited samples to an $\mathrm{SiCl}_{4} \mathrm{Ar}$ discharge. Direct proof of the dependence of etch rate $\left(r_{E}\right)$ on the chlorine concentration is shown in Fig. 8.

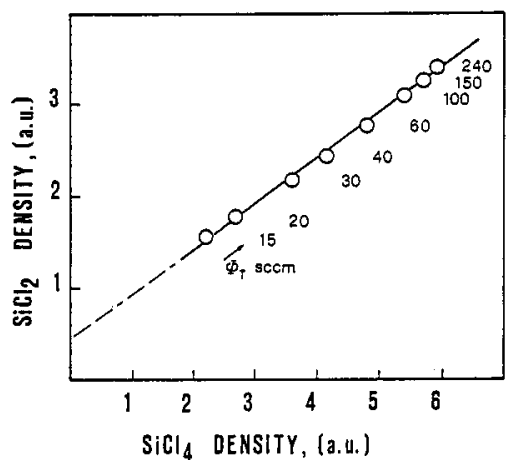

Fig.7 -Relationship between $\mathrm{SiCl}_{2}$ and $\mathrm{SiCl}_{4}$ density measured at different total flow rate $\Phi_{\mathrm{T}}$.

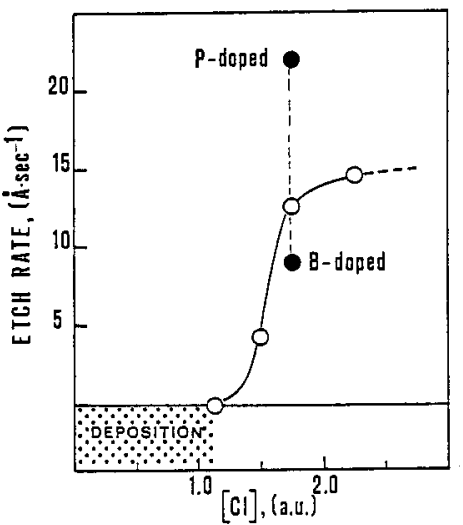

Fig. 8 -Etch rate of $\mathrm{Si}: \mathrm{H}, \mathrm{Cl}$ films vs chlorine atom density [Cl]. Filled circles refer to the etch rate of $\mathrm{P}$ - and B-doped samples.

The two points reported for phosphorous and boron doped samples show a strong dependence of the etch rate on the $\underline{n}$ and $\underline{p}$ character of the material. This result, together with the "plateau" region exhibited by $r_{F}$ values is indicative of the presence of a $\mathrm{Cl}$ atom chemisorption process, which can proceed up to the saturation of the surface coverage. A similar doping effect has been reported by Flamm et al. (ref.30), who attributed its origin to the ionic character of the silicon-halogen bond. Furthermore, the extrapolation to zero value of $r_{E}$ when $\mathrm{Cl}$ atoms are still present, reveals a contemporary occurrence of etching and deposition, due to the competition of chemisorbed $\mathrm{Cl}$ and silicon bearing species. The reactions to be added to the previous model which are responsible of the etch process are:

$$
\mathrm{Cl}(\text { gas }) \rightleftharpoons \mathrm{Cl}(\mathrm{ads})
$$

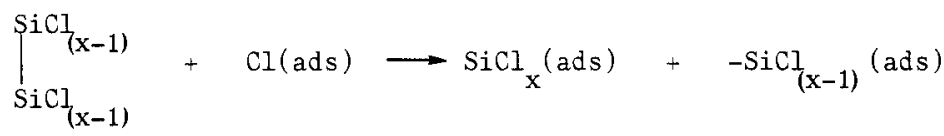

where $\mathrm{SiCl}_{\mathbf{x}}$ (ads) species rapidly desorb, according to the equilibrium (10).

The fact that the surtace bombardment by charged particles can control the rate of the 
overall deposition process has been invoked to explain recent data obtained in $\mathrm{SiF}_{4}-\mathrm{H}_{2}$ glow discharge (ref.19). The effect of the total pressure on the density of the gas phase species as obtained by OES and MS and on the deposition rate is reported in Fig. 9.

Argon density has been obtained by correcting the emission intensity by its partial pressure; the trend obtained can be representative of both the electron and the ion density profiles. The decrease of the deposition rate with pressure cannot be explained on the basis of a chemical model involving only neutral species, therefore an ion assisted mechanism has to be invoked. This is well illustrated in the figure in which the $r$ profile is similar to that of Ar density (i.e. ion density), but not to the trends of neutral species. This result, together with further experimental evidence (ref. ), suggests a deposition model very similar to the one proposed for the $\mathrm{SiCl}_{4}$ system:

$$
\mathrm{SiF}_{4}(\operatorname{gas}) \rightleftharpoons \mathrm{SiF}_{4}(\text { ads }) \stackrel{\text { ions }}{\longrightarrow} \mathrm{SiF}_{\mathbf{x}}(\text { ads }) \stackrel{\mathrm{H}}{\longrightarrow} \text { film }
$$

the only difference being that the rate limiting step is the ion assisted dissociative chemisorption. Once again $\mathrm{H}$ atoms play the important role of halogen scavengers both in the gas phase and on the surface, in order to assist film growth. In fact, under conditions of high fluorine atom density, $i . e$. of low amounts of $\mathrm{H}_{2}$ in the feed, the plasma exhibits the well known transition from deposition to etching mode. Also in plasma etching systems it has been found that the overall kinetics can be driven by chemical and/or ionic channels (refs.30-32).

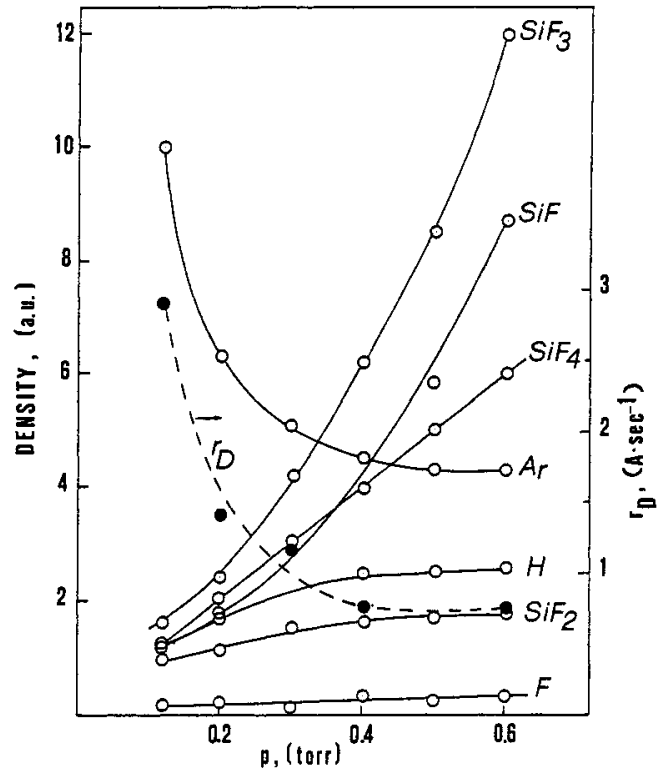

Fig.9 -Trends of $\mathrm{SiF}_{\mathrm{X}}, \mathrm{F}$ and $\mathrm{H}$ density and of the deposition rate, $r_{D}$ vs total pressure, $\mathrm{p}$ in $\mathrm{SiF}_{4}-\mathrm{H}_{2}(10: 1)$. The trend of absolute intensity of the Ar, normalized to its partial pressure, is also reported. $\left(11 \mathrm{sccm}, 20\right.$ watts, $\left.T_{D}=300^{\circ} \mathrm{C}\right)$.

Finally, it has been shown that, once the growth precursors are chemisorbed on the surface, the deposition proceeds through reactive and unreactive steps involving neutral and ionic particles. Nevertheless, the overall surface kinetics will depend only on the rate-limiting step. We have reported that a kinetic analysis can in some cases $\left(\mathrm{SiCl}_{4}-\mathrm{H}_{2}\right.$ system) reveal the chemical channel, in others ( $\mathrm{SiF}_{4}-\mathrm{H}_{2}$ system) the ionic channel.

\section{Microscopic parameters affecting the material properties}

The need to thoroughly understand the role of external parameters on the deposition mechanism arise from the fact that, besides affecting growth kinetics, they also have a great influence on the chemical and physical properties of the material. It is well known, for example, how optical and structural properties of amorphous silicon films are strictly related to substrate temperature and to some microscopic parameters, which in turn affect the deposition rate.

One of the main arguments which many workers seem to agree about is that ion bombardment of the film surface during growth, not onlys chemically affects the process (see preceding section), but also has a large physical effect on the evolution of the film properties. Hence, the importance of measuring the electrical characteristics of the plasma, such as the electron (or ion) concentration $\left(n_{e}\right)$ and energy (ref.32) or the electron energy distribution function (edf) (ref.33,45) and the plasma potential (ref.34). Consequently a great amount of interest is directed to the control of the substrate bias. 
Recently, the determining role of edf and $n$ has been stressed in a detailed study of the effect of the plasma excitation frequency $(25-150 \mathrm{MHz})$ on the deposition rate as well as on chemical, optical and electrical material properties (ref.35). A large variation of $r_{\text {with }}$ the frequency has been found with a maximum value $\left(r_{-}=20 \AA / \mathrm{sec}\right)$ around $70 \mathrm{MHz}$, where $\mathrm{D}$ good quality material is obtained. An explanation for this has been given by considering the change of the electron distribution function induced by the frequency variation and therefore of the electron concentration at a given energy (ref.36).

Within the same framework a deposition rate of about $250 \AA / \mathrm{sec}$ obtained in electron cyclotron resonance (ECR) plasma (ref.37) can be seen for a-Si:H films of device quality. Also in the frequency range of microwaves a remarkable value of deposition rate $\left(r_{D}>100\right.$ $\AA / \mathrm{sec}$ ) has been obtained for a-Si:H,F films (ref.38) and their relevant quality has been attributed to the high plasma density of free radical film precursors achieved in the reactor without formation of gas phase polymers.

The effect of the substrate bias has been extensively investigated by many workers (refs.26,39,40). K. Ando et al. (ref.40) have utilized a triode system which can control the negative bias of the substrate without changing the other deposition conditions. The increase of incident ion flux caused by a negatively enhanced bias is responsible for the improvement of the photovoltaic quality of the material. This effect was related to the increase of $\mathrm{SiH}$ incorporation with respect to $\mathrm{SiH}_{2}$ in the material (ref.41). Similar results have been reported by other authors (refs.42,43), who found that the increase of ion bombardment energy favours the formation of high density homogeneous and isotropic films with the predominance of $\mathrm{SiH}$ groups. On the contrary, some authors have shown that the increase of $\mathrm{SiH}$ incorporation is obtained by decreasing the electron and ion bombardment (ref.44) or their energy (ref.46). These controversial findings selected from the literature show that some aspects of this argument are still debatable.

\section{CONCLUDING REMARKS}

We have emphasized that the existing problems regarding the plasma deposition of amorphous silicon films is often caused by the absence of a complete characterization of the system under investigation. The difficulty of comparing results from different groups is a consequence of the fact that only macroscopic parameters are generally reported to identify the deposition system. In our opinion, an attempt should be made to measure the microscopic parameters, such as electron concentration, electron energy distribution function and plasma and surface potentials, which are the real "fingerprints" of the plasma system.

\section{Acknowledgements}

We express our gratitude to Dr. G. Cicala for her enthusiastic work, to Prof. R. d'Agostino for helpful discussions and to Prof. F. Cramarossa for his constant encouragement. This work has been partially supported by "Progetto Finalizzato Energetica II - CNR".

\section{REFERENCES}

1. G.Turban, Pure \& Appl. Chem., 56, 215-230 (1984).

2. J.J. Wagner and S. Veprek, Plasma Chem. \& Plasma Process., 3, 219-234 (1983).

3. F.J. Kampas and R.W. Griffith, J.Appl. Phys., 52, 1285-1288 (1981); F.J.Kampas and R.W. Griffith, Appl. Phys. Lett., 39, 407-409 (1981).

4. G. Turban, Y. Catherine, and B. Grolleau, Thin Solid Films, 67, 309(1980).

5. R. Robertson and A Gallagher, J. Appl. Phys, 59, 3402-3411 (1986).

6. P.A. Longeway, R.D. Estes, and H.A. Weakliem, J.Phys. Chem., 88, 73-77 (1984).

7. S. Veprek, K. Ensslen, M. Konuma, and F.A. Sarott, Proc 7th Int.Symp. on Plasma Chem. (ISPC-7), Eindhoven 1985, C.J. Timmermans, Ed.; Eindhoven University, p.74-78 (1985).

8. J. Perrin, T. Broekhuizen and R. Benfehrat, Proc. of European-MRS Conference, Strasbourg (France) (1986).

9. T. Hamasaki, M.H. Hirose, H. Kurata, M. Taniguchi, and Y. Osaka, Jpn. J. Appl. Phys., 20, 281-285 (1981).

10. M.J. Kushner, Plasma Processing, (MRS Symp.Proc. Vol. 68); J.W.Coburn, R.A.Gottscho, and D.W.Hess, Eds.; (MRS Pittsburg) p.99 (1986). 
11. N.Mutsukura, M. Ohuchi, S. Satoh and Y. Machi, Thin Solid Films, 109, 47-57 (1983).

12. H.U. Lee, J.P. Deneufville, and S.R. Ovshinsky, J. Non-Cryst. Solids, 59-60, 671 (1983).

13. H.U. Lee, J.P. Deneufville, J. Non-Cryst. Solids, 66, 39-44 (1984).

14. G. Bruno, P. Capezzuto, G. Cicala, and F. Cramarossa, Plasma Chem.\& Plasma Process., $\underline{6}, 109-125(1986)$.

15. G. Bruno, P. Capezzuto, G. Cicala, and F. Cramarossa, Thin Solid Films, 135, 245-250 (1986).

16. G. Bruno, P. Capezzuto, G. Cicala, and F. Cramarossa, J.Appl. Phys.,00, 00(1987).

17. R. d'Agostino, F. Cramarossa, S. De Benedictis and F. Fracassi, Plasma Chem. \& Plasma Process., $4163(1984)$

18. N. Mayo, U. Carmi, I. Rosenthall, R. Avni, R. Manory, and A. Grill, J. Appl. Phys., 55, 4404 (1984).

19. G. Bruno, P. Capezzuto, G. Cicala, and F. Cramarossa, Proc. 8th Int. Symp. on Plasma Chem. (ISPC-8), to be published.

20. A. Madan, S.R. Ovshinsky, and E. Benn, Philos. Mag., B40, 259 (1979).

21. H. U. Lee, R.C. Ross, and J.P. Deneufville, Plasma Processing (MRS Symp. Proc. Vol.68) J.W. Coburn, R.A. Gottscho, and D.W. Hess, Eds.; (MRS Pittsburgh)p. 149 (1986).

22. K.J. Laidler, Catalysis, Vol.I,P.H. Emmett, Ed.; Reinhold, New York (1954).

23. R. Manory, E. Grossmann, R. Avni, and E. Grill, Thin Solid Films, 121, 135-141 (1984).

24. T. Hamasaki, M. Ueda, M. Hirose, and Y. Osaka, J. Non-Cryst. Solids, 59-60, 679 (1983).

25. J. Qiao, z. Jiang, and z. Ding, J. Non-Cryst. Solids, 77-78, 829-832 (1985).

26. S. Veprek, Proc. MRS-Europe, Strasbourg 1984, P. Pinard and S. Kalbitzer Eds., Les Editions de Physique, Les Ullis, France, 425 (1984).

27. J.C. Knights, J. Non-Cryst. Solids, 35-36, 159 (1980).

28. A. Madan, private communication.

29. G. Bruno, P. Capezzuto, G. Cicala, and F. Cramarossa, Proc. 7 th E.C. Photovoltaic Solar Energy Conf.(Sevilla 1986), A. Goetzberger, W. Palz and G. Willeke Eds., Reidel Pub., Holland, 1208 (1986).

30. D.L. Flamm and V.M. Donnelly, Plasma Chem.\& Plasma Process., 1, 317 (1981).

31. H.G. Stenger, JR. and G.S. Akiki, Plasma Processing, (MRS Symp. Proc., Vol. 68), J.W. Coburn, R.A. Gottscho, and D.W. Hess Eds. (MRS Pittsburg) p.267 (1986).

32. J.W. Coburn, Plasma Chem. \& Plasma Process., 2, 1-42 (1982).

33. A. Garscadden, Plasma Processing, (MRS Symp. Proc., Vol. 68) J.W. Coburn, R.A. Gottscho, and D.W. Hess Eds. (MRS Pittsburgh) p.127 (1986)

34. K. Kohler, J.W. Coburn, D.E. Horne, and E. Kay, J. Appl. Phys., 57, 59-66 (1985).

35. H. Curtins, M. Favre, N. Wyrsch, M. Brechet, K. Prasad, and A.V. Shah, Proc. 19th IEEE Photovoltaic Specialists Conference, New Orleans, (1987).

36. H. Curtins, N. Wyrsch, M. Favre and A.V. Shah, Plasma Chem. \& Plasma Process., 00, (1987).

37. S. Kato and T. Aoki, J. Non-Cryst. Solids, 77-78, 813-816(1985).

38. S.J. Hudgens, A.G. Johncock, and S.R. Ovshinsky, J.Non-Cryst. Solids, 77-78, 809-812(1985)

39. A. Matsuda, J. Non Cryst. Solids, 59-60, 767-774(1983).

40. K. Ando, M. Aozasa, and R.G. Pyon, Appl. Phys. Lett., 44, 413-415(1984).

41. K. Satoni, R.G. Pyon, M. Aozasa and K. Ando, Memoirs of the Faculty of Engineering Osaka City University, 25, 33-43(1984).

42. B. Drevillon, J. Huc andf N. Boussarssar, J. Non-Cryst. Solids, 59-60, 735-738(1983).

43. P. Roca i Cabarrocas, A.M. Antoine, B. Drevillon, and J.P.M. Schmitt, Proc. 7 th Int. Symp on Plasma Chem., (ISPC-7), (Eindhoven 1985) C.J. Timmermans Ed., Eindhoven University, p.74 (1985).

44. K. Tsuji, S. Minomura, T. Hiraga, A. sekiguchi and M. Nagasaka, J. Non-Cryst. Solids, 59-60, 691-694(1983).

45. P. E. Vanier, F.J. Kampas, R.R. Cordermann, and G. Rajeswaran, J.Appl. Phys., 56, 1812-1820 (1984).

46. M. Taniguchi, M. Hirose, T. Hamasaki and Y. Osaka, Appl. Phys. Lett., 37, 787-788(1980).

47. A. Matsuda, T. Kaga, H. Tanaka, L. Malhotra, and K. Tanaka, Jpn. J. Appl. Phys., 22, L115-L117 (1983).

48. G. Turban, Y. Catherine and B. Grolleau, Thin Solid Films, 67, 309-320(1980); ibidem $\underline{77}$, 287-300 (1981).

49. F.J. Kampas, Bull. Am. Phys., 27, 208 (1982).

50. R. Manory, A. Grill, U. Carmi and R. Avni, Plasma Chem. \& Plasma Process., 3, 235, (1983) 